This item was submitted to Loughborough's Research Repository by the author.

Items in Figshare are protected by copyright, with all rights reserved, unless otherwise indicated.

\title{
Zinc whisker growth from electroplated finishes - a review
}

PLEASE CITE THE PUBLISHED VERSION

http://dx.doi.org/10.1179/0020296715Z.000000000227

\section{PUBLISHER}

(c) W.S. Maney \& Son Ltd.

\section{VERSION}

AM (Accepted Manuscript)

\section{PUBLISHER STATEMENT}

This work is made available according to the conditions of the Creative Commons Attribution-NonCommercialNoDerivatives 4.0 International (CC BY-NC-ND 4.0) licence. Full details of this licence are available at: https://creativecommons.org/licenses/by-nc-nd/4.0/

\section{LICENCE}

CC BY-NC-ND 4.0

\section{REPOSITORY RECORD}

Wu, L., Mark A. Ashworth, and G.D. Wilcox. 2015. "Zinc Whisker Growth from Electroplated Finishes - a Review". figshare. https://hdl.handle.net/2134/18303. 


\title{
Zinc whisker growth from electroplated finishes --- A review
}

\author{
L. Wu*, M. A. Ashworth and G. D. Wilcox \\ Department of Materials, Loughborough University, Loughborough, Leicestershire, LE11
} 3TU

*Corresponding author,

Email: $\underline{\text {.wu@lboro.ac.uk }}$

Tel: $\quad+44(0) 1509$ 


\section{Abstract}

Electroplated zinc finishes have been associated with the electronics industry for many years as a result of their excellent corrosion resistance and relatively low cost. They are normally applied onto ferrous products to provide corrosion protection in a range of different environments. However, the formation of spontaneously grown whiskers on zinc electroplated components, which are capable of resulting in electrical shorting or other damaging effects, can be highly problematic for the reliability of long life electrical and electronic equipment. The growth of zinc whiskers has been identified as the cause of some electrical and electronic failures in telecommunications and aerospace based applications, with consequences ranging from mild inconvenience to complete system failures. Investigators have been striving to address the problems induced by whisker growth since the 1940s. However, most research effort has been focused on tin whiskers; especially following European Union environmental legislation that restricted the use of lead $(\mathrm{Pb})$, which when alloyed with tin ( 3 - 10\% by weight) provided effective tin whisker mitigation. Compared with tin whisker research, much less attention has been paid to zinc whiskers. A number of mechanisms to explain zinc whisker growth have been proposed, but none of them are widely accepted and some are in conflict with each other. The aim of this paper is to review the available literature in regard to zinc whiskers; to discuss the reported growth mechanisms, to evaluate the effect of deposition parameters and to explore potential mitigation methods. This paper presents a chronologically ordered review of zinc whisker related studies from 1946 to 2013. Some important early research, which investigated whisker growth in tin and cadmium, as well as zinc, has also been included.

Keywords: whisker growth, zinc, review, electrodeposition 


\section{Introduction}

Metal whiskers are spontaneous growths that can develop from metal surfaces. Whisker growth after deposition should not be confused with the dendritic growths that can sometimes occur during the process of electrodeposition or as a result of electrochemical migration in electronic devices. It has been observed that tin, zinc and cadmium surfaces, in particular in the form of electroplated coatings, are prone to develop whiskers. Whiskers have also been found growing from other metal surfaces including indium and gold [1]. Normally, metal whiskers undergo an unpredictable incubation period ranging from hours to years, followed by an approximately constant growth rate [1]. The growth morphologies of whiskers are unpredictable; whiskers can grow straight or form kinked or curved eruptions (Figure 1). They may also form hillocks or eruptions with particularly complex shapes such as pyramids and spiral filaments. In this review, the term "eruptions" is used to refer to whiskers that form in the shape of curved growths after electrodeposition, which are different from the nodulelike growths that are formed during electrodeposition of zinc. With respect to whisker dimensions, they are thinner than a human hair and virtually invisible to the naked eye. The typical dimension of a whisker is 1 to $5 \mu \mathrm{m}$ in diameter and 1 to $500 \mu \mathrm{m}$ in length. In rare cases, whiskers have grown longer than $10 \mathrm{~mm}$ [2].

Whisker growth is not a new phenomenon; it can be traced back to the 1940s when the presence of cadmium whiskers resulted in the breakdown of radio systems used in aircraft during WWח [3]. Since then, the study of metallic whiskers has become of great interest to investigators. Many electrical and electronic failures have been attributed to the presence of these small metallic growths, with consequences ranging from mild inconvenience to complete system failures. During the past 70 years, researchers have been striving to address the problems induced by metal whisker growth and a considerable number of whisker-related papers have been published. However, most research has, until recently, focused on tin 
whiskers and today whisker growth on tin is a well-documented but not totally understood phenomenon. This is because tin has long been used as a surface finish on electrical and electronic components, where whisker growth is particularly problematic. Very little attention has been paid to zinc whiskers, due to zinc finishes being applied to applications that were considered less sensitive.

During the last two decades, many electronic failures (Table 1 [4]), especially computer equipment failures in Canada in 2003 [5] and the Colorado Secretary of State's office in 2004 [6], were attributed to problems induced by zinc whiskers from the bottom surface of zincelectroplated steel floor tiles. It is now recognised that zinc whiskers are a potential threat to the reliability of long life electrical and electronic equipment, particularly for aerospace, power plant and telecommunications applications. Consequently, the number of published studies with respect to zinc whiskers has increased significantly. A summarised history of key zinc whisker publications is shown in Table 2.

\section{Early whisker research}

Electrical failures caused by metal whisker growth were first discovered during WWח due to the choice of cadmium (Cd) as an electroplated coating on electronic components inside aircraft radios. These failures were published in a 1946 paper by Cobb [3], who reported that the leaves in capacitors used in the radios were electroplated with cadmium, and over time long whiskers had formed on the surface of these components. These long filament-type whiskers, which are highly electrically conductive, resulted in an electrical short between adjacent capacitor plates and hence caused the radio system to fail.

In 1948, similar failures were found by the Bell Telephone Corporation on some of their channel filters used in carrier telephone systems [7]. These electronic failures resulted in considerable difficulties in the operation of a transmission channel. The only solution was to 
replace the filters with a new unit. The failed filters were sent for examination at Bell Laboratories. The failure analysis was published in a 1951 paper by Compton, Mendizza and Arnold [7]. This paper was a landmark since it made a number of important summary statements, which were to guide future investigations into metal whiskers. The paper established that whisker formation was not limited to cadmium electroplated components, but had also been found on zinc and tin electrodeposits, and also on an aluminium casting alloy. Compton, Mendizza and Arnold also suggested that metal coatings applied by other methods, e.g. sprayed, evaporated and hot dipped coatings had similar propensities for whisker formation. They also proposed that whiskers were not compounds, but spontaneous growths of single crystals of the same metal as that from which they were formed. For example, they found that whiskers growing from zinc metal surfaces were single zinc crystals with a close packed hexagonal structure. It is also worth noting that, in this 1951 paper, Compton, Mendizza and Arnold stated that tin whiskers developed more quickly than zinc and cadmium whiskers. This might be one of the reasons that the vast majority of subsequent research focussed on tin whiskers, while very little attention was paid to other metal whiskers in the following years.

In 1953, the first mechanism for whisker growth was proposed by Peach [8], who stated that each whisker contained a screw dislocation and metal atoms migrated and deposited themselves at the whisker tip, in the form of spiral growth. However, this hypothesis was disproved by Koonce and Arnold [9] when they published the first electron microscope micrographs of whiskers growing over several weeks, which suggested that whiskers grew from the base. Since then, it is widely accepted that whisker growth occurs due to the continual migration of metal atoms to the base of the whisker.

An important contribution to developing a mechanism for whisker growth was outlined in a 1954 paper by Fisher, Darken and Carroll [10]. This was a breakthrough since, for the first 
time, it was reported that whisker growth was a form of mass transport, driven by compressive stress gradients that were developed by externally applied pressures. Metal atoms were prone to migrate from a region with a high compressive stress to a low compressive stress region, where atoms piled up and formed the whisker base. Based on the compressive stress mechanism, Fisher, Darken and Carroll concluded that whiskers were single crystals spontaneously growing at a linear rate that was determined by the magnitude of an externally applied pressure.

In 1956, Arnold [11] published a review paper that summarised all the whisker-related observations made at Bell Laboratories up to that date. He studied the effect of several experimental parameters on whisker growth (e.g. exposure to elevated temperature, relative humidity, coating deposition methods, coating thickness and substrate material characteristics) and stated that each of the factors had only a slight influence on whisker growth. It is also worthy of note that the author proposed several whisker mitigation strategies for the first time in the published literature. Arnold aimed to reduce whisker growth by the application of a variety of thin coatings onto the metal surface (e.g. oil, greases, silicones, waxes, lacquers, and chromate conversion coatings on zinc and cadmium). However, he reported that whiskers penetrated through all the coatings, especially at the edge or where cracks developed. Even though his mitigation strategies failed to effectively inhibit whisker growth, this was the onset of whisker mitigation research and paved the way for later investigations.

In 1957, Baker [12] reported his studies on the distribution of angular bends on whiskers formed on the surface of zinc, tin and cadmium electroplated components. Prior to this study, the growth directions of whiskers had rarely been published. Baker found that the bend angle distribution had peaks equal to the angles between low-indices directions in the crystal lattice. He concluded that the crystal structures of zinc, tin and cadmium whiskers were not coherent 
with that of the base material and that the angular bends formed in whiskers were due to a change in the growth direction at the base of a whisker.

In 1966, Ellis [13] published a paper regarding the morphologies and growth directions of tin, zinc and cadmium whiskers. A number of common growth directions for tin, zinc and cadmium whiskers were reported in this paper. Further, by comparing spontaneously grown whiskers and vapour-grown filamentary crystals, Ellis concluded that the growth directions for whiskers were low index crystallographic directions, the majority of which were consistent with those for vapour-deposited crystals and also corresponded to the glide plane indices in plastic flow. These results were used to support the whisker growth mechanisms that were based on dislocation models.

\section{Zinc whisker research}

The first theories to explain zinc whisker growth were proposed by Lindborg in the 1970s, who published a set of monographs solely on zinc whisker topics [14-16]. Lindborg is one of the very few researchers to have paid considerable attention to zinc whiskers. In 1975, Lindborg [15] produced a paper that studied the driving force for whisker growth from zinc coatings electrodeposited on carbon steel substrates. He proposed that whisker formation was driven by the internal macrostress of the deposit, which was built into the zinc film during electroplating. He further suggested that whisker growth was indeed a form of mass transport to relieve built-in internal compressive macrostress and the growth rate was associated with the magnitude of the macrostress. Experimental data showed that for a macrostress less than

$45 \mathrm{~N} / \mathrm{mm}^{2}$ the growth rate was relatively low, whilst above $55 \mathrm{~N} / \mathrm{mm}^{2}$ the growth rate became notably higher. Another key finding was the role of microstructural variables on zinc whisker growth (e.g. grain size, microhardness and microstrain). He proposed that zinc whisker growth was only associated with the built-in macrostresses and that microstructural variables 
had very little influence. However, these results were obtained from a limited number of specimens and the reproducibility was comparatively low. Therefore, such findings could not be considered conclusive. In this paper, Lindborg [15] also investigated the effect of the crystallographic orientation of zinc electrodeposits on whisker growth. X-ray diffraction (XRD) analysis suggested that zinc grains tended to be orientated with a plane $\{11 \overline{2} 0\}$ parallel to the plane of the surface and the crystallographic texture $\{11 \overline{2} 0\}$ appeared to be favourable for zinc whisker formation and growth.

In 1976, Lindborg [16] published another paper that put forward a model for zinc, cadmium and tin whisker growth. The author reiterated that the predominant driving force for whisker growth was the compressive macrostress produced during electroplating and a two-stage model, consisting of a diffusion stage and a glide stage, was necessary for all metal whisker growth. In the diffusion stage, a dislocation loop will expand laterally by climb as vacancies are emitted away from the loop. When the expanding loop reaches a size corresponding to the whisker cross-section, it starts to glide towards the surface. Based on the model, Lindborg suggested that a whisker was pushed up one atomic step as each dislocation loop reached the surface of the growing whisker.

Following Lindborg's observation that zinc whisker formation and growth was driven by internal compressive macrostress, several related studies were published in the following years. In 1984, an important publication by Sugiarto, Christie and Richards [17] reported on zinc whisker formation and growth from bright cyanide zinc electrodeposits, and for the first time showed a series of scanning electron microscope (SEM) micrographs of zinc whiskers. Sugiarto et al. stated that bright zinc electrodeposits stored at room temperature were highly susceptible to whisker growth. They further suggested that organic materials derived from the brightener system were capable of producing compressive microstress in the deposit, which 
was responsible for whisker formation and growth, whilst dull zinc electrodeposits without organic materials present did not develop whiskers. Based on these observations, they concluded that the predominant driving force for zinc whisker formation and growth was the microstress derived from organic materials present in the zinc electrodeposits, and that the macrostress of the deposit was not associated with whisker formation and growth.

Another important aspect of the Sugiarto et al. paper was that it reported the first investigations into the role of thermal treatment on zinc whisker growth [17]. A recognised problem with whisker research is considered to be the delay before whisker growth can be detected. Sugiarto et al. found that a thermal treatment of $175^{\circ} \mathrm{C}$ for 24 hours immediately after electroplating was an effective method to accelerate whisker growth from zinc electrodeposits in the short term. Samples were divided into two groups. Some were stored at room temperature (Group I samples) and others were subjected to a post-electroplating thermal acceleration treatment prior to being stored at room temperature (Group П samples). In the initial examination (24 hours after electroplating), they found that whiskers on Group $\Pi$ samples had grown more rapidly than those on Group I samples. However, after 240 days storage, the average growth rate of whiskers on the Group $\Pi$ samples had become lower than that on the Group I samples and some whiskers on the Group П samples had not grown since the initial examination. Although Sugiarto et al. attempted to accelerate zinc whisker growth via a post-electroplating thermal treatment, their observations showed that a thermal treatment of $175^{\circ} \mathrm{C}$ for 24 hours straight after electroplating only accelerated whisker growth initially. In the long term, however, there was no difference in whisker growth between the two groups of samples.

Another key observation by Sugiarto et al. was that zinc whisker growth could be temporarily retarded by either the application of passivation coatings (i.e. chromate conversion coatings) or pre-electroplating processes (e.g. heat treatment of steel substrates prior to zinc 
electroplating to relieve the stress in the substrate). However, these two methods could not completely inhibit long term zinc whisker growth. After 90 days storage, whisker growth was detected on both the passivated and the pre-treated samples. Hence, Sugiarto et al. issued a warning that zinc whiskers were problematic for the long term reliability of electrical and electronic components that were electroplated with bright zinc coatings. The Sugiarto et al. paper is important because it is the first paper to discuss zinc whisker mitigation. With regard to tin whisker mitigation, a number of mitigation strategies have been developed over the years that include the co-deposition of lead $(\mathrm{Pb})$ in tin $(\mathrm{Sn})$ coatings, metal underlays and conformal polymeric coatings. However, very little information can be found in the literature in relation to zinc whisker mitigation.

Two papers were published at the end of 1980s regarding the relationship between the crystallographic orientation of zinc electrodeposits and subsequent whisker growth from them. In 1986, Takemura et al. [18] published a study that highlighted the relationship between the crystallographic orientation of zinc coatings electrodeposited on steel substrates and the growth directions of the resultant whiskers. They showed data which indicated that zinc whiskers on their samples exhibited a $<1000>$ growth direction and concluded that deposits with crystallographic textures of $\{10 \overline{1} 0\}$ and $\{11 \overline{2} 0\}$ were favourable for zinc whisker growth. Takemura et al. stated that their results were consistent with observations that whiskers not only grow perpendicular to the surface, but also were found growing inclined to the normal of the surface with an angle of approximately $60^{\circ}$. This paper, for the first time, correlated the crystallographic orientation of zinc electrodeposits with the growth directions of zinc whiskers.

In the same year, Takemura et al. [19] published another paper, which reported that the nature of the substrate materials (low-carbon steel, silicon steel, amorphous ferrous material and cast zinc bars) and the thickness of electroplated zinc coatings had a strong influence on both the 
crystallographic characteristics of the deposit and subsequent whisker growth. Experimental results suggested that, when the deposit thickness was less than $10 \mu \mathrm{m}$, the choice of substrate material had a strong effect on the crystallographic orientation of the deposit. When the deposit thickness was greater than $10 \mu \mathrm{m}$, the influence of the substrate materials was significantly decreased and deposits on different substrates were found to possess the same preferred crystallographic texture $\{11 \overline{2} 0\}$. With respect to the effect of deposit thickness on whisker growth, they reported that the number of whiskers increased dramatically as the deposit thickness was increased from $3 \mu \mathrm{m}$ to $10 \mu \mathrm{m}$, while when the deposit thicknesses was greater than $10 \mu \mathrm{m}$, the number of whiskers was gradually reduced.

A paper published in 1990 by Nagai et al. [20] provided measurements of microstrain and macrostress in zinc electrodeposits and discussed the influence of these two parameters on zinc whisker growth. The microstrain was measured using the Hall plot method [21] and their experimental data inferred that microstrain did not have an influence on zinc whisker growth. Macrostress in the deposit was measured by means of X-ray macrostress measurements and bending strain methods. Nagai et al. found that the X-ray macrostress measurements obtained by measuring lattice compression were not reliable and suggested that the bending strain method was simpler and more reliable. Their bending strain data indicated that a larger macrostress contributed to a higher zinc whisker growth rate. A considerable number of zinc whiskers were found on samples having a macrostress of more than $60 \mathrm{MPa}$. These observations with respect to the influence of microstrain and macrostress on whisker growth rate were in agreement with the earlier Lindborg study [15].

In 1991, Garner et al. [22] of the Harshaw Chemical Company reported their studies of zinc whisker growth on both alkaline cyanide and acid chloride zinc electrodeposits. Their company was part of a programme to solve the problem of why decorative zinc electrodeposits, applied onto refrigerator shelf hardware, unexpectedly became "hazy" in 
appearance. Low cyanide zinc electrodeposits were coated with lacquer and thermally treated at $175^{\circ} \mathrm{C}$ for 15 minutes to cure the lacquer. It was observed that originally bright aselectroplated deposits became "significantly hazy" in appearance during heat treatment and continued to become more "hazy" for several hours. Further, they found that a higher current density and a greater deposit thickness could result in more "hazy" appearance. Garner et al. speculated that the change in appearance was induced by the formation and growth of zinc whisker eruptions and filaments. They established a series of experiments to investigate whisker growth from both alkaline cyanide and acid chloride zinc electrodeposits and presented some results regarding the influence of deposit thickness, deposition current density, solution temperature and macrostress on zinc whisker growth. These observations were consistent with the earlier Sugiarto et al. study [17] and the importance of this paper is that it gave a warning that zinc electroplated components were susceptible to whisker growth when subjected to a thermal treatment straight after deposition.

In 1994, an important paper was published by Downs and Francis [23] that outlined a zinc whisker related lawsuit between a medical-device maker and a rotary switch manufacturer. They reported on the failure of rotary switches used in medical components, which was traced to the growth of zinc whiskers on the surface of the switch that had induced short circuiting. The rotary switch manufacturer had been aware that tin and cadmium electroplated components had propensities for whisker growth, but had no idea about the phenomenon of zinc whisker growth. Hence, initially, they could not explain the cause of the failure and spent hundreds of hours examining this unexpected failure. They stated that problems caused by zinc whisker growths had not appeared previously because the rotary switches had been widely applied in high-voltage applications, under which zinc whiskers were electrically burnt-out and eliminated. However, in more recent years, the majority of rotary switches had been used in low-voltage applications, and as a result zinc whiskers had survived and given 
rise to electronic failures. This paper was not academically significant, but did strongly underline the potential failures that could be induced by zinc whiskers.

Since the turn of the century, zinc whisker research has been more widely studied due to an increasing number of electronic equipment failures that have been attributed to zinc whisker growth.

Reynolds and Hilty [24] published a paper in 2004 that for the first time investigated zinc whiskers by means of a focused ion beam (FIB) technique. They presented a series of FIB images showing cross-sectioned zinc electrodeposits on carbon steel substrates, which appeared to suggest that both the zinc electrodeposits and the whiskers growing from them were polycrystalline and fine grained (sub-micron). This observation is significant because it showed for the first time that metal whiskers were not always single crystals but could also be polycrystalline, which conflicted with the widely accepted belief that had been held for many years [7]. However, based on their FIB results, it is not clear whether the whiskers were single crystals or not, since their cross-sectional images showing metal whiskers were not of sufficiently high quality. The paper also discussed the influence of intermetallic compounds on zinc whisker growth. It is widely acknowledged that the formation and continual growth of intermetallic compounds at the interface between tin electrodeposits and copper substrates is one of the major driving forces for tin whisker growth [25-27]. However, the effect of intermetallic formation has not been widely reported with respect to the growth of zinc whiskers. Based on their FIB images, Reynolds and Hilty reported that iron-zinc intermetallic compounds were not present at the Fe/Zn interface, and further concluded that intermetallic compounds did not appear to be associated with whisker growth from zinc electrodeposits on carbon steel substrates. 
Between 2005 and 2007, a series of papers regarding the driving force for zinc whisker growth from hot-dip galvanised (HDG) zinc coatings and bright zinc electrodeposits were published by Lahtinen and Gustafsson [28-30], who for the first time, presented experimental evidence for whisker growth from HDG coatings, as shown in Figure 2. It was observed that the inner surfaces of HDG steel pipes were populated with long filament type whiskers (up to $10 \mathrm{~mm}$ in length), after being stored in a warehouse for more than 15 years.

Lahtinen and Gustafsson [28-30] suggested that compressive stress, derived from a thermal expansion mismatch, could be an important factor in whisker growth on both zinc electrodeposits and HDG coatings. Two factors were considered noteworthy, a) the large difference in the coefficients of thermal expansion (CTE) of zinc crystals between the a-axis and the c-axis and b) the difference in CTEs between the substrate material (iron) and the zinc coating. These two factors were thought to be responsible for the generation of thermal stresses when subjected to temperature fluctuations. Lahtinen and Gustafsson further proposed that both dull HDG coatings and electroplated coatings with brighteners were more prone to develop whiskers, since larger thermal stresses were detected in their coating layers.

The effect of surface contaminants on zinc whisker growth was also studied by Lahtinen and Gustafsson [28-30], who reported that chlorine and sulphur were detected in the areas of whisker growth on both HDG coatings and zinc electrodeposits. Their energy dispersive Xray (EDS) analysis data showed that the chlorine levels were greater than sulphur levels near the whisker root and in regions where numerous zinc whiskers were observed, whilst in regions with little or no whisker growth, chlorine levels were lower. They suggested that chlorides derived from contaminants on the surface were associated with whisker growth, since a chloride pit was found to form near the root of each long filament whisker. Lahtinen and Gustafsson stated that chlorides were able to disrupt the passive layer exposing the zinc 
deposit and thereby resulted in the corrosion of zinc coatings, which might facilitate whisker growth.

In 2009, a paper regarding the influence of thermal treatment on zinc whisker growth was published by Chapaneri et al. [31], which studied the growth of whiskers from bright acid chloride-based zinc electrodeposits when subjected to elevated temperatures. They observed that a large number of zinc whiskers were present on samples that were exposed to $150^{\circ} \mathrm{C}$ for 1 hour after deposition, whilst no whisker growth was detected on similar samples stored at room temperature. They suggested that thermal treatment at $150^{\circ} \mathrm{C}$ for 1 hour could significantly facilitate, rather than mitigate, whisker growth from bright acid zinc electrodeposits.

The published research with regard to the role of thermal treatment on zinc whisker growth suggests that a post-electroplating thermal treatment would accelerate rather than mitigate whisker growth from zinc electrodeposits [17][22][31]. However, for tin whiskers, it is generally accepted that a post-electroplating thermal treatment is able to reduce tin whisker growth. The first evidence that thermal treatment could be used as a tin whisker mitigation method was reported by Glazunova in 1962 [32], who suggested that samples treated at $100^{\circ} \mathrm{C}$ for more than 6 hours or at $150^{\circ} \mathrm{C}$ for more than 2 hours were much less prone to develop whiskers. Britton [33] in his 1974 paper proposed that thermal treatment at $200^{\circ} \mathrm{C}$ for 1 hour completely prevented whisker growth on tin-electroplated copper for a period of 5 years. In 1975, Sabbagh and McQueen [34] reported a negative influence of thermal treatment on tin whisker mitigation. They observed that, after 6 years, whisker growth was observed on both tin-electroplated steel exposed at $165^{\circ} \mathrm{C}$ for 3 hours and tin-electroplated copper exposed at $194^{\circ} \mathrm{C}$ for 4 hours. Hence, they concluded that a post-electroplating 
thermal treatment was capable of slowing down tin whisker growth, but could not completely prevent whiskering.

Since it is known that whisker growth is a function of a complex relationship of various key parameters (e.g. electrodeposit chemistry, storage conditions and post-electroplating treatment), it is difficult to ensure the reproducibility of whisker growth testing between different studies and this is a major problem for whisker related research.

In 2009, a paper regarding the role of intermetallic compounds on zinc whisker growth was published by Baated, Kim and Suganuma [35], who studied zinc-electroplated steel raised floor tiles that had been used in a computer data centre for over 10 years. By means of electron probe micro analysis (EPMA) and X-ray diffraction analysis (XRD), they observed that both iron-zinc (Fe-Zn) intermetallic compounds and zinc oxides were present. They reported that Fe-Zn intermetallic compounds were not only formed at the interface between the zinc film and the substrate, but also within the electroplated zinc coatings themselves. This observation was not consistent with the widely accepted premise that intermetallic compounds were only formed at the coating/substrate interface. They accounted for this anomaly by suggesting that Fe atoms must migrate from the substrate and diffuse into the deposit, and subsequently react with zinc to form the intermetallic compounds. With respect to the distribution of zinc oxides, the majority of them were observed on the deposit surface. Based on their observations, Baated, Kim and Suganuma proposed a growth mechanism that highlighted the influence of Fe-Zn intermetallic compounds and zinc oxides, which could result in the development of compressive stresses within the deposit and the diffusion of zinc atoms towards the surface. Subsequent whisker growth occurred from the surface to relieve the stress. This proposition was in conflict with Reynolds and Hilty's study in which no FeZn intermetallic compound formation had been observed [24]. 
In 2010, Baated, Kim and Suganuma [36] published another paper that presented further experimental evidence to support their mechanism for zinc whisker growth. Elemental analysis of the same samples by FIB and TEM-EDX techniques confirmed that Fe-Zn intermetallic compounds had formed throughout the entire electroplated zinc coatings, which could result in a compressive stress in the zinc film and promote whisker growth from the surface. In this paper, Baated, Kim and Suganuma [36] also suggested some potential mitigation methods, based on their assumption that Fe-Zn intermetallic compounds formed in the electroplated zinc layer and the Fe/Zn interface were responsible for whisker growth. Their proposals included a) the application of a diffusion boundary layer (e.g. a nickel layer) between the zinc deposit and the steel substrate that could prevent the formation of Fe-Zn intermetallic compounds, b) the introduction of a high-temperature heat treatment after deposition that could result in a uniform intermetallic compound layer and stress relief and c) the application of a physical barrier (e.g. metal nanofilm or conformal coating) on the surface to inhibit whisker growth.

In 2012, another important paper regarding the role of intermetallic compounds on zinc whisker growth was published by Fortier and Pecht [37], who reported on a comparative study of different metal films (tin, zinc and cadmium) and their propensities for subsequent whisker growth. By investigating zinc-electroplated samples that were thought to be $15-20$ years old, they found that a considerable number of large whiskers were present on the surface of zinc-electroplated steel components. Analysis of the cross-sectional microstructure using FIB showed that a layer of Fe-Zn intermetallic compound was present at the interface between the zinc film and the steel substrate, but it was very thin $(<<1 \mu \mathrm{m})$ and did not continue to increase in size over time. Fortier and Pecht concluded that Fe-Zn IMCs were present at the coating/substrate interface, but they were not associated with whisker growth; unlike the case of Sn-Cu IMCs in Sn films. This proposition was clearly not consistent with 
the earlier study by Baated et al. [35]. Fortier and Pecht stated that whisker growth was associated with the oxidation that occurred on the deposit surface [37]. They rationalised that the oxidation process produced voids near the surface, which then diffused downwards into the zinc film. The inward diffusion of the voids caused zinc atoms to migrate upwards to the surface and form whiskers. This assumption was supported by their FIB and TEM analysis, which showed a number of voids present in the microstructure of the zinc film beneath a whisker.

Etienne et al. [38] in 2012 proposed a whisker growth model based on recrystallisation. Their samples, fabricated in 1982, were low alloy carbon steel substrates electroplated with $10 \mu \mathrm{m}$ zinc coatings, which were subsequently treated with a $200 \mathrm{~nm}$ chromate conversion coating. It was observed that a number of filament type whiskers had formed from eruptions and grown up to $8 \mathrm{~mm}$ in length after approximately 30 years in service. By measuring residual stresses in the sample using XRD, Etienne et al. reported that a compressive stress of $30 \pm 9$ MPa was measured in the zinc film, which was lower than that in a freshly deposited zinc film (51 to $71 \mathrm{MPa}$ [39]). They suggested that stress relaxation occurred in the deposit as whiskers were growing from the surface and whisker growth was essentially to relieve the compressive stress within the zinc film. To understand the mechanism for zinc whisker growth, Etienne et al. used focused ion beam (FIB) and electron backscatter diffraction (EBSD) techniques to characterise the cross-sectional microstructure both far from a whisker and at the root of a whisker. It was observed that the zinc deposit far from a whisker was comprised of columnar grains, whilst in the vicinity of the whisker root the grain size was generally increased and oblique grain boundaries were present. In addition, grains near the whisker root did not exhibit the same crystallographic orientation as those away from whiskers. Based on these observations, they stated that the grains near the whisker root were recrystallised and they further proposed that recrystallisation was closely associated with zinc 
whisker formation and growth. This statement is consistent with several tin whisker growth mechanisms based on recrystallisation [13, 40, 41].

In 2013, Etienne et al. [42] presented additional experimental results to support their proposed growth mechanism based on recrystallisation. They first investigated a sample that was extracted at the root of a filament type whisker growing directly from the deposit surface. They found that zinc grains near the whisker root were recrystallised. More surprisingly, cavities were observed within the zinc coating (up to $\sim 9 \mu \mathrm{m}$ under the surface). The volume of the cavities was much smaller than that of the filament whisker; i.e. atoms coming from the cavities were not sufficient to produce the whisker. Based on this result, Etienne et al. confirmed that a long-range diffusion mechanism was associated with zinc whisker growth. A further sample was investigated, which contained a filament type whisker growing from a eruption. They reported that grains at the whisker root and in the whisker eruption were both recrystallised and exhibited the same characteristics, which further strengthened their proposed whisker growth mechanism based on recrystallisation.

\section{Conclusions}

Compared with tin whisker investigations, much less research effort has been focused on zinc whiskers. Some zinc whisker growth mechanisms have been proposed, but the results of such studies are often conflicting and there is, at present, no widely accepted growth mechanism in place. Also, there are very few investigations into the role of parameters (e.g. substrate materials, electrodeposit characteristics and storage conditions) that may be associated with zinc whisker growth and it is still not clear how these parameters affect the propensity of a deposit to grow whiskers. The development of whisker mitigation strategies is limited due to the incomplete understanding of zinc whisker formation and growth mechanisms. Postelectroplating thermal treatment, which has been identified as an effective mitigation method 
for tin whiskers, was, however, found to promote zinc whisker growth. Other potential mitigation methods such as conformal polymeric coatings and metal underlays have been proposed to address zinc whisker growth. However, it is not known how effective such mitigation strategies would be, since there is no related research in the literature.

\section{Acknowledgements}

The authors would like to thank the UK EPSRC Innovative Electronics Manufacturing Research Centre for funding this research through the WHISKERMIT programme at Loughborough University. 


\section{References}

[1] M. Sampson, H. Leidecker: 'Basic Information Regarding Tin Whiskers', NASA, 2009 available at: nepp.nasa.gov/whisker/background/index.htm, [Accessed at: 09-Feb-2013]

[2] 'NASA Goddard Tin Whiskers', 2012 available at: nepp.nasa.gov/whisker/photos/index.html, [Accessed at: 09-Feb-2013]

[3] H. L. Cobb: 'Cadmium Whiskers', Mon Rev. Am. Electroplat. Soc., 1946, 33, 28-30.

[4] 'NASA Goddard Tin Whiskers', 2011 available at: nepp.nasa.gov/whisker/other_whisker/index.htm\#zinc, [Accessed at: 09-Feb-2013]

[5] S. Tucker: 'The Case of the “Zinc Whiskers”', Canada's Health-care Newspaper, 2003, www.hospitalnews.com/the-case-of-the-zinc-whiskers/, [Accessed at: 10-Feb-2013]

[6] A. Svaldi: 'Zinc “Whiskers” Cause Computer Outages in Colorado State Offices', Knight Ridder/Tribune Business News, 2004 available at: www.highbeam.com/doc/1G1-118857697.html, [Accessed at: 10-Feb-2013]

[7] K. G. Compton, A. Mendizza, S. M. Arnold: 'Filamentary Growths On Metal Surfaces - “Whiskers ”', Corrosion, 1951, 7, 327-34.

[8] M. O. Peach: 'Mechanism of Growth of Whiskers on Cadmium', J. Appl. Phys. 1952, 23, 1401.

[9] S. E. Koonce, S. M. Arnold: 'Growth of Metal Whiskers', J. Appl. Phys., 1953, 24, 365.

[10] R. Fisher, L. Darken, K. Carroll: 'Accelerated Growth of Tin Whiskers', Acta Metall., 1954, 2, 368-72.

[11] S. M. Arnold: 'The Growth and Properties of Metal Whiskers', Proc. 43rd Annual Convention of the American Electroplater's Sociaty, Washington, DC, USA, June 1956, American Electroplater's Society, 26-31.

[12] G. S. Baker: 'Angular Bends in Whiskers', Acta Metall., 1957, 5, 353-7.

[13] W. C. Ellis: 'Morphology of Whisker Crystals of Tin, Zinc, and Cadmium Grown Spontaneously from the Solid', Trans. Metall. Soc. AIME, 1966, 236, 872-875.

[14] U. Lindborg, S. Ramsin, L. Lind, L. Revay: 'Microstructure and Metallurgical Properties of Some Zinc Electroplates', Plating, 1974, 61, 1111-1116.

[15] U. Lindborg: 'Observations on the Growth of Whisker Crystals from Zinc Electroplate', Metall. Trans. A, 1975, 6A, 1581-1586.

[16] U. Lindborg: 'A Model for the Spontaneous Growth of Zinc, Cadmium and Tin Whiskers', Acta Metall., 1976, 24, 181-186. 
[17] H. Sugiarto, I. R. Christie, B. P. Richards: 'Studies of Zinc Whiskers Formation and Growth from Bright Zinc Electrodeposits', Trans. Inst. Met. Finish., 1984, 62, 92-97.

[18] T. Takemura, M. Kobayashi, O. Masayuki, T. Kakeshita, K. Shimizu: 'Relation Between the Direction of Whisker Growth and the Crystallographic Texture of Zinc', Jpn. J. Appl. Phys., 1986, 25, 1948-1949.

[19] T. Takemura, M. Kobayashi, M. Okutani: 'Influence of Base Materials on the Characteristics of Zinc Electroplates and the Whisker Formation', Jpn. J. Appl. Phys., 1986, 25, 1439-1440.

[20] T. Nagai, K. Natori, T. Furusawa: 'Approximation for the Rate of Short Circuit in Electronic Devices Caused by Whisker Growth on Zn Electroplated Steel', Fujitsu. Sci. Tech. J., 1990, 26, 107-113.

[21] W. H. Hall: 'X-ray Line Broadening in Metals', Proc. Phys. Soc., 1949, 62A, 741-743.

[22] H. R. Garner, D. Dickie, C. W. Skimin: 'Whisker Growth from Decorative Zinc Electrodeposits', A working Paper of the Harshaw Chemical Company, Cleveland, U.S.A., 1991.

[23] J. Downs, R. Francis: 'The Phenomenon of Zinc Whisker Growth and the Rotary Switch', Met. Finish., 1994, 23-25.

[24] H. L. Reynolds, R. Hilty: 'Investigations of Zinc Whiskers using FIB Technology', IPC/JEDEC Lead-Free North Am. Conf., Boston, MA, 2004, 1-21.

[25] K. N. Tu: 'Interdiffusion and Reaction in Bimetallic Cu-Sn Thin Films', Acta Metall., 1973, 21, 347-354.

[26] K. N. Tu, R. D. Thompson: 'Kinetics of Interfacial Reaction in Bimetallic Cu-Sn Thin Films', Acta Metall., 1982, 30, 947-952.

[27] B. Z. Lee, D. N. Lee: 'Spontaneous Growth Mechanism of Tin Whiskers', Acta Mater., 1998, 46, 3701-3714.

[28] R. Lahtinen, T. Gustafsson: 'The Driving Force Behind Whisker Growth', Met. Finish., 2005, 103, 33-36.

[29] R. Lahtinen, T. E. Gustafsson: 'The Driving Force Behind Whisker Growth', Met. Finish., 2005, 103, 25-29.

[30] R. Lahtinen, T. E. Gustafsson: 'SEM Investigation of Zinc Whiskers on Hot-dip Galvanized Coatings and Bright Electroplated Coatings', J. Appl. Surf. Finish., 2007, 2, 15-19.

[31] R. Chapaneri, A. J. Ebbage, G. D. Wilcox, G. W. Critchlow, A. Chojnicki, T. Pearson, A. J. Rowan: 'Effect of Heat Treatment on Promoting Zinc Whisker Growth from Bright Zinc Electrodeposited Coatings', Trans. Inst. Met. Finish., 2009, 87, 159-162. 
[32] V. K. Glazunova: 'A Study of the Influence of Certain Factors on the Growth of Filamentary Tin Crystals', Transl. from Krist., 1962, 7, 761-8.

[33] S. C. Britton: 'Spontaneous Growth of Whiskers on Tin Coatings: 20 Years of Observation', Trans. Inst. Met. Finish, 1974, 52, 95-102.

[34] N. A. J. Sabbagh, H. J. McQueen: 'Tin Whiskers: Causes and Remedies', Met. Finish, 1975, 3, 27-31.

[35] A. Baated, K. S. Kim, K. Suganuma: 'Investigation of Mechanism for Spontaneous Zinc Whisker Growth from an Electroplated Zinc Coating', Proc. Int. Conf. Electron. Packag. Technol. \& High Density Packag., Beijing, China, 2009, 1019-1022.

[36] A. Baated, K. S. Kim, K. Suganuma: 'Whisker Growth from an Electroplated Zinc Coating', J. Mater. Res., 2010, 25, 2175-2182.

[37] A. Fortier, M. G. Pecht: 'Comparative Study of Metal Films and Their Affinity for Metal Whisker Growth', IEEE Trans. Comp. Packag. Manuf. Technol., 2012, 2, 739747.

[38] A. Etienne, E. Cadel, A. Lina, L. Cretinon, P. Pareige: 'Crystallographic Characterization of an Electroplated Zinc Coating Prone to Whiskers', IEEE Trans Comp. Packag. Manuf. Technol., 2012, 2, 1928-1932.

[39] A. Lina, M. Mahe: 'Essai en Enceinte Climatique Pour L'etude de la Formation et de la Croissance des Whiskers de Zinc et de Cadmium. EDF, Moret. Sur. Loing. Cedex Fr. Tech. Rep., 2009, referenced from Etienne, Cadel, Lina, Cretinon and Pareige ${ }^{38}$.

[40] N. Furuta, K. Hamamura: 'Growth Mechanisms of Proper Tin-Whisker', Jap. J. App. Phys., 1969, 9, 1404-1410.

[41] J. Smetana: 'Theory of Tin Whisker Growth: The End Game', IEEE Trans. Electr. Packag. Manuf., 2007, 30, 11-22.

[42] A. Etienne, E. Cadel, A. Lina, L. Cretinon, P. Pareige: 'Micro- and Nanostructure of Zn Whiskers and Their Coating', J. Electr. Mater., 2012, 42, 272-279.

[43] B. Julian: 'Zinc Whiskers Tangle Data Centre Ops', Computerworld, 2004 available at: www.computerworld.com.au, [Accessed at: 15-Apr-2013]

[44] 'Zinc Whisker Induced Failures in Electronic Systems', ERA Technology, 2012, www.era.co.uk, [Accessed at 15-Apr-2013] 

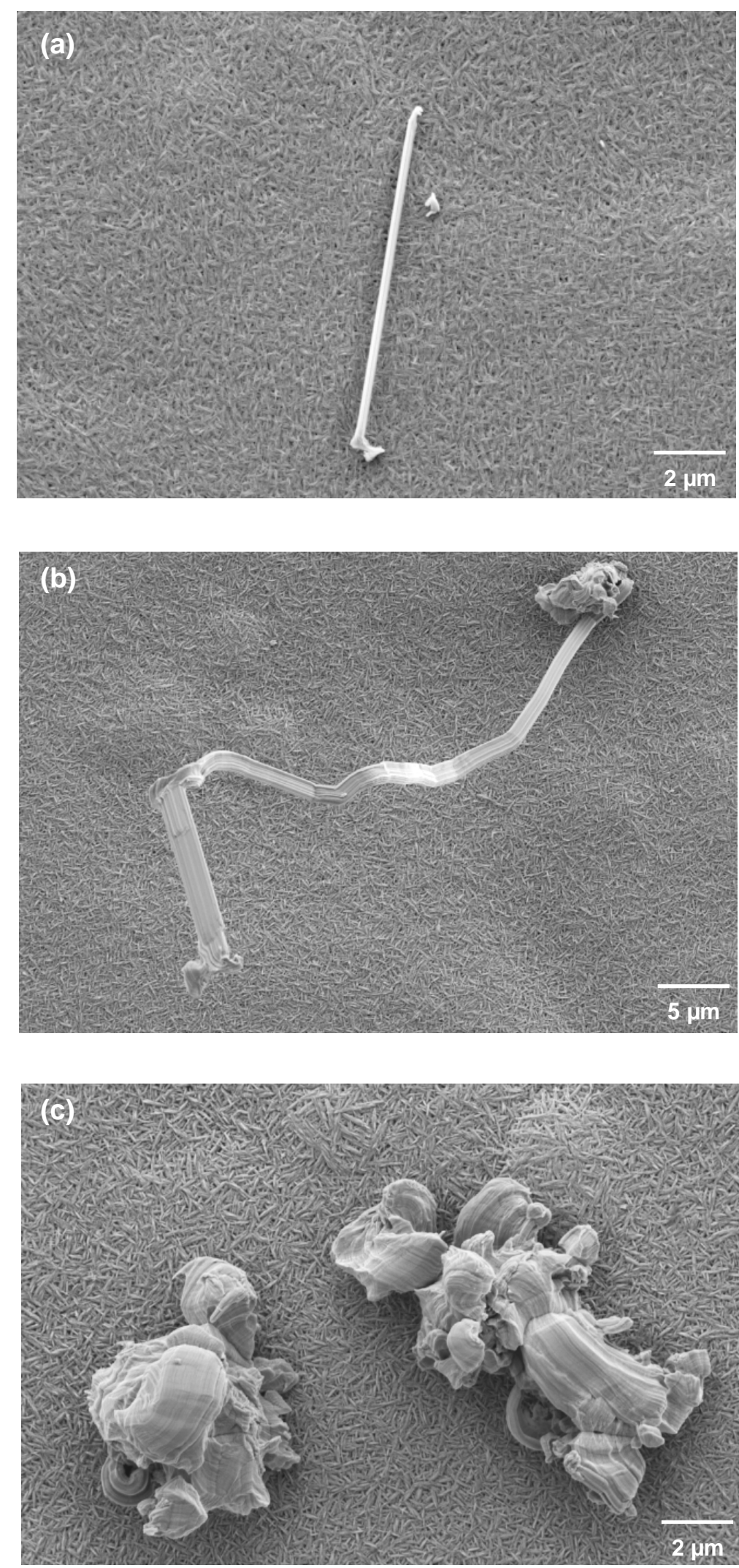

Figure 1 SEM images showing examples of different zinc whisker morphologies: a) a straight filament whisker; $b$ ) a curved filament whisker and $c$ ) two odd-shaped whisker eruptions 

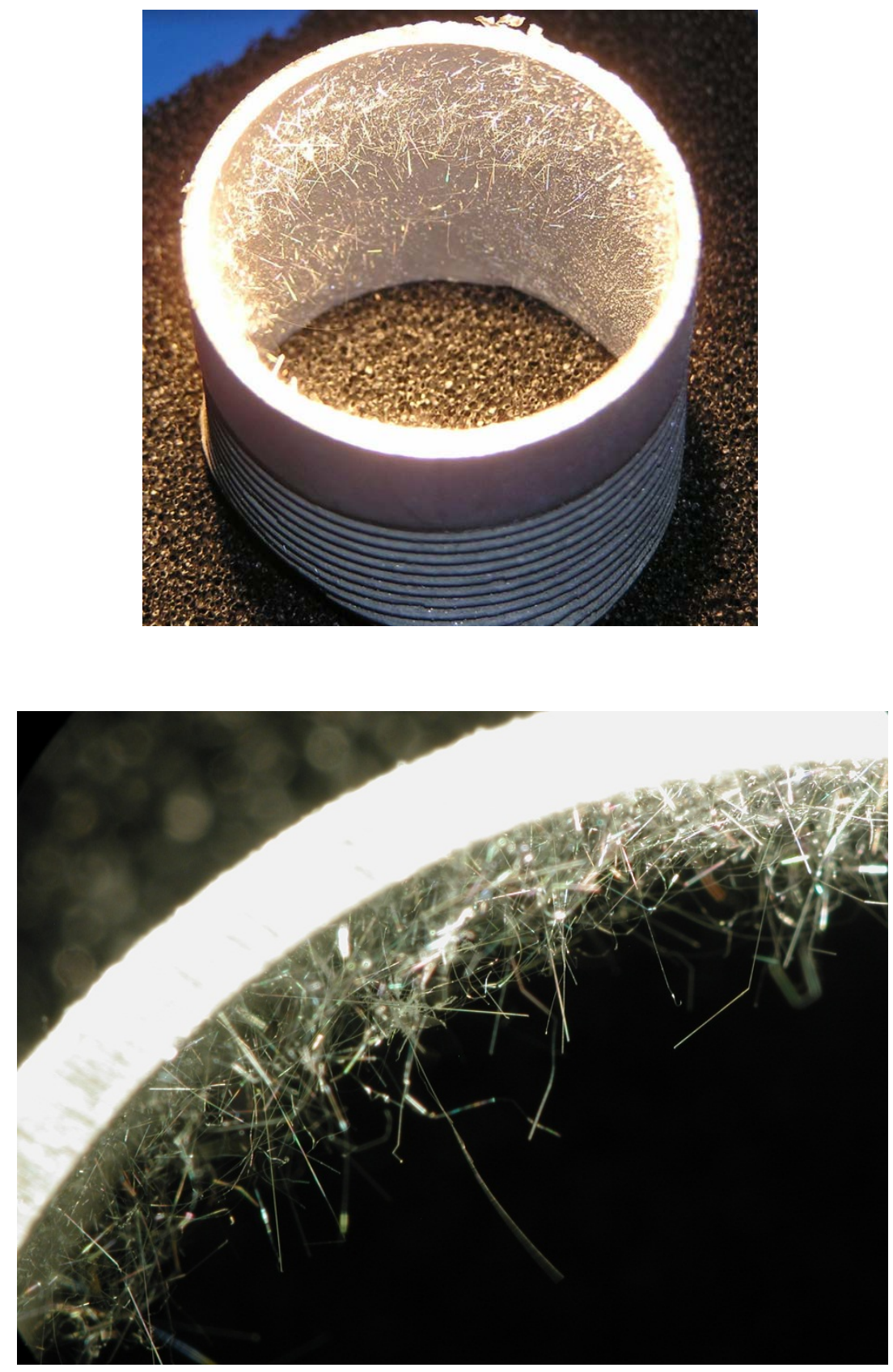

Figure 2 Images showing inner surfaces of hot-dip galvanised steel pipes densely populated with filament-type zinc whiskers (some longer than $10 \mathrm{~mm}$ in length) after being stored in a warehouse for more than 15 years, images courtesy of the NASA Electronic Parts and Packaging (NEPP) Program http://nepp.nasa.gov/whisker 
Table 1 Reported electronic failures caused by zinc whiskers, based on the information from Reference [4]

\begin{tabular}{|c|c|c|}
\hline Year & Whiskers on & Applications \\
\hline 1987 & $\begin{array}{l}\text { Local Power Range Monitoring } \\
\text { (LPRM) Detectors }\end{array}$ & Dresden nuclear Power Station \\
\hline 1990 & Rotary Switch & Apnea Monitors \\
\hline 1990 & $\begin{array}{l}\text { Local Power Range Monitoring } \\
\text { (LPRM) Detectors }\end{array}$ & Duane Arnold Nuclear Power Station \\
\hline 1995 & Framework & Telecom Equipment \\
\hline 1996 & Chassis & Computer Routers \\
\hline 1998 & Chassis & Computer Hardware \\
\hline 1999 & Xsistor Package + Standoff & Missiles \\
\hline 1999 & Chassis & Computer Routers \\
\hline 2001 & Bus Rail & Space Ground Test Equipment \\
\hline 2003 & Floor Tiles & Computer Data Centre in Canada [5] \\
\hline 2004 & Floor Tiles & Computer Data Centre in USA [6] \\
\hline 2004 & Floor Tiles & Computer Data Centre in Australia [43] \\
\hline 2012 & Floor Tiles & $\begin{array}{l}\text { Computer Data Centre in North East } \\
\text { England [44] }\end{array}$ \\
\hline
\end{tabular}


Table 2 Abbreviated history of published work in regard to zinc whiskers

\begin{tabular}{|c|c|}
\hline Year & Summary of the findings \\
\hline 1975 & $\begin{array}{l}\text { The first report on the growth mechanisms of zinc whiskers was published } \\
\text { by Lindborg, who proposed that whisker formation and growth from zinc } \\
\text { electrodeposits was driven by the built-in internal macrostress [15]. }\end{array}$ \\
\hline 1984 & $\begin{array}{l}\text { Sugiarto et al. suggested that the predominant driving force for zinc whisker } \\
\text { formation and growth was the microstress derived from organic materials } \\
\text { present in the zinc electrodeposits [17]. }\end{array}$ \\
\hline 1986 & $\begin{array}{l}\text { Takemura et al. published two papers studying, firstly, the effect of zinc } \\
\text { electrodeposit crystallographic orientation on whisker growth and secondly, } \\
\text { the influence of different substrate materials on whisker growth[18][19]. }\end{array}$ \\
\hline 1990 & $\begin{array}{l}\text { Nagai et al. published work detailing the measurement of microstress and } \\
\text { macrostress in zinc electrodeposits and the influence of these two } \\
\text { parameters on whisker growth [20]. }\end{array}$ \\
\hline 1994 & $\begin{array}{l}\text { An important paper was published by Downs and Francis that outlined a } \\
\text { zinc whisker related lawsuit between a medical-device maker and a rotary } \\
\text { switch manufacturer. This paper highlighted the potential failures that could } \\
\text { be induced by zinc whiskers [23]. }\end{array}$ \\
\hline 2004 & $\begin{array}{l}\text { Reynolds and Hilty published a paper that, for the first time, investigated } \\
\text { zinc whiskers using a focused ion beam (FIB) technique. Their results } \\
\text { suggested that iron-zinc intermetallic compounds were not associated with } \\
\text { whisker growth from zinc electrodeposits on carbon steel substrates [24]. }\end{array}$ \\
\hline $2005-2007$ & $\begin{array}{l}\text { Lahtinen and Gustafsson for the first time presented experimental evidence } \\
\text { for whisker growth from hot-dip galvanised coatings. They proposed that } \\
\text { compressive stress, derived from a thermal expansion coefficient mismatch, } \\
\text { is an important factor in whisker growth on both zinc electrodeposits and } \\
\text { HDG coatings [28][29][30]. }\end{array}$ \\
\hline 2009 & $\begin{array}{l}\text { Chapaneri et al. reported that a post-electroplating thermal treatment at } \\
150^{\circ} \mathrm{C} \text { for } 1 \text { hour could significantly promote whisker growth from bright } \\
\text { acid zinc electrodeposits [31]. }\end{array}$ \\
\hline $2009-2010$ & $\begin{array}{l}\text { Baated et al. published a paper highlighting the role of intermetallic } \\
\text { compounds and surface oxides on zinc whisker growth and proposed } \\
\text { potential mitigation methods [35][36]. }\end{array}$ \\
\hline $2012-2013$ & $\begin{array}{l}\text { A whisker growth model based on recrystallisation was proposed by } \\
\text { Etienne et al., who found that zinc grains near the whisker root were } \\
\text { recrystallised [38][42]. }\end{array}$ \\
\hline
\end{tabular}

